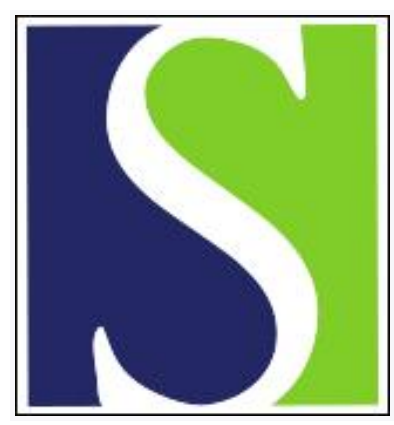

Scand J Work Environ Health 1981;7(3):169-178

https://doi.org/10.5271/sjweh.3109

Issue date: Sep 1981

A case-referent study on acute myeloid leukemia, background radiation and exposure to solvents and other agents

by Flodin U, Andersson L, Anjou C-G, Palm U-B, Vikrot O, Axelson O

Key terms: acute myeloid leukemia; agent; animal contact; background radiation; case-control design; case-referent design; case-referent study; exposure; gamma radiation; leukemia; lowdose radiation; pesticide exposure; radiation; solvent; solvent exposure; $\mathrm{X}$-ray exposure

This article in PubMed: www.ncbi.nlm.nih.gov/pubmed/20120581 


\title{
A case-referent study on acute myeloid leukemia, background radiation and exposure to solvents and other agents
}

\author{
by Ulf Flodin, MD, ${ }^{1}$ Lennart Andersson, ${ }^{1}$ Carl-Göran Anjou, BSc, ${ }^{2}$ \\ Ulla-Britt Palm, BA, ${ }^{1}$ Olle Vikrot, $M D,{ }^{3}$ Olav Axelson, MD '
}

\begin{abstract}
FLODIN U, ANDERSSON L, ANJOU C-G, PALM U-B, VIKROT O, AXELSON O. A case-referent study on acute myeloid leukemia, background radiation and exposures to solvents and other agents. Scand $j$ work environ health 7 (1981) 169-178. The effect of potential risk factors for acute myeloid leukemia was evaluated in a case-referent study encompassing 42 cases and 244 referents, all deceased. Information on exposure was obtained with questionnaires mailed to the next of kin. Particularly the effect of background radiation was evaluated, as assessed with a gamma radiation index weighing the time spent outdoors and indoors and considering the building material (stone, wood, etc) in the homes and the workplaces of the subjects. Especially between the ages of 20 and 49 a, to some extent also between 50 and 69 a but not above 70 , there seemed to be an effect from background radiation and a trend suggesting an exposureeffect relationship. There was also about a sixfold increase in the rate ratio with regard to solvent exposure, which also seemed to modify the effect of background radiation. Other exposures were associated with relatively modest increases in the rate ratios and/or very small numbers of exposed individuals. It would be worthwhile to undertake further cancer epidemiologic studies of background radiation in which effective study designs are applied and a variety of potential confounders and modifiers of effect are identified and accounted for.
\end{abstract}

Key terms: animal contacts, case-referent (case-control) design, gamma radiation, lowdose radiation, pesticide exposure, solvent exposure, X-ray exposure.

Epidemiologic studies of leukemia have focused on genetic, infectious, and environmental risk factors. Thus a familial aggregation tends to occur $(13,25)$, and there are some suggestions of a viral etiology $(11,16)$, particularly in relation to contacts with cats, poultry and cattle. Exposure to benzene seems to be associated with an increased risk of leukemia $(19,34)$, especially of the acute myeloid type, but also other, more ill-defined exposures to

1 Department of Occupational Medicine, University Hospital, Linköping, Sweden.

2 Department of Medical Informatics, University Hospital, Linköping, Sweden.

3 Department of Internal Medicine, University Hospital, Linköping, Sweden.

Reprint requests to: Prof O Axelson, Department of Occupational Medicine, University Hospital, S-581 85 Linköping, Sweden. petroleum products might be of etiologic importance (6). Ionizing radiation has been firmly established as a cause of leukemias of all types except the chronic lymphatic kind $(8,23)$, but it is still rather unclear whether or not low-level radiation might play an etiologic role in the development of leukemia $(9,21)$.

The principal question of the etiologic role of background radiation in cancer causation has gained further interest during the past few years in view of recent concerns about increasing indoor concentrations of radon as a potential lung cancer hazard. A preliminary observation of an association between lung cancer and stone-house residency, as presumably reflecting higher exposure to radon and its daughters $(3,4)$, and a puzzling finding of an increased rate ratio for leukemias among office personnel in a city in south- 
ern Sweden (5), a phenomenon that could be related to background indoor radiation, have provoked our interest for further studies in this respect. This case-referent (case-control) study of acute myeloid leukemia (International Classification of Disease 1965, ICD 205,00), and particularly background radiation, reflects this interest and is part of an attempt to study leukemias in relation to various occupational and environmental exposures.

\section{Material and methods}

The general principles followed in this investigation have already been described in a methodological paper (2). More specifically, the study considers various exposures, especially background radiation, among individuals deceased from acute myeloid leukemia and among individuals deceased from other causes of death, malignancies excluded, within the county of Ostergötland and during the period 1972-1978. The county of Östergötland is a low land area about $50-150 \mathrm{~m}$ above sea level and located in southeastern Sweden; there is differentiated industry, but also farming and some forestry.

\section{Source of subjects}

The cases were primarily obtained from the Linköping University Hospital register of deaths, and all individuals with acute myeloid leukemia diagnosed during the study period were included. In a second step, these cases were identified in the parish registers of deaths and burials, îrom which the referents were then chosen (all deaths are registered in the home parishes, irrespective of where the individual has died). The number of available cases amounted to 46 , out of which one newly deceased individual was directly excluded for ethical reasons.

Six referents for each case were chosen from the parish registers; they were those in the nearest three register positions before and after each case if they fulfilled certain requirements. Thus they should be of the same gender as the case and similar in age ( \pm 7 a) and without a cancer diagnosis according to the death certificate, since there might be relationships between cancer and the various risk factors for leukemia and the inclusion of cancer diagnoses among the referents would then result in a distortion of the exposure frequency among the referents as compared to the source population of the cases.

In one rather small parish no individuals fulfilled these criteria, and therefore also the case from this parish was excluded. For another case there were only five individuals available as referents and another three referents turned out to have been selected more than once. Therefore, 44 cases and 260 referents remained for the study. However, out of these 304 subjects, one case was found to have lived abroad for a very long time, and another had suffered primarily from a multiple myeloma and had been treated with cytotoxic agents. These two cases were therefore excluded. Thus the material for the study encompassed 42 cases and 260 referents as selected through a procedure providing a reasonable homogeneity of the material with regard to age, gender, and domicile.

\section{Assessment of exposure}

Information about various types of exposure among the cases and referents was obtained with a nine-page questionnaire, preceded by an introductory letter and sent out by mail to the next of kin. The questionnaire contained 30 main questions, out of which 15 concerned occupational exposures, some of them further subspecified with regard to certain details. Four questions were devoted to medical care, particularly the use of drugs and X-ray examinations and treatments. Furthermore, smoking habits were asked for. Aspects about residency were covered in six main questions, and another four questions were given in reference to various environmental aspects, leisure-time activities, etc, as well as information about urban or rural domicile during the lifetime of the individual. Of the referents sent the questionnaire, 16 were not included in the final analyses, five due to refusal to participate, five due to inability of the next of kin to reply to the questionnaire, and another three due to the impossibility to trace the next of kin, since the mailing address turned out to be incorrect. Two referents had very recently died and were therefore excluded for 
ethical reasons, and one referent was found to be a recent immigrant; thus information was finally obtained from 42 cases and 244 referents.

\section{Classification of exposure}

For the main purpose of revealing confounding and modification of effect, various potential risk factors for the disease were evaluated on the basis of the exposure situation of the subjects during the 20 a prior to death (table 2). The exposure to background radiation was assessed with a radiation index created to estimate exposures $5-25$ a prior to death. For five subjects younger than 25 a, the remaining time period was considered. In principle the background gamma radiation was accounted for in this index, but there should also be a relatively good positive correlation with radon and radon daughters, although not known to be of importance for the development of leukemia.

The use of a "time window" in looking at exposure allows for an induction-latency requirement and also leads to the disregarding of remote exposure which might have little or no effect on the development of acute myeloid leukemia; this view would be consistent with the incidence of leukemia peaking about a decade after exposure among the Japanese A-bomb survivors (32).

A couple of Swedish investigations (17, 33) have shown that the gamma radiation in wooden houses is rather similar to outdoor background radiation the average absorbed dose being about $1 \mathrm{mGy} / \mathrm{a}$ or 0.1 $\mathrm{rad} / \mathrm{a}$, cosmic radiation included), whereas stone houses seem to produce about double of that exposure and plastered houses and brick houses are in between.

The gamma radiation index was assessed blindly for the subjects with regard to case-referent status and was timeweighted over the years with respect to outdoor and indoor work, leisure time being spent outdoors or indoors and type of residency; furthermore the contribution to the exposure from various types of building materials at workplaces and in homes was estimated. More specifically, one-third of the time was assumed to have been devoted to three main activities, ie, work, "leisure time," and sleeping. The gamma radiation index being denoted by GRI, the estimated background radiation dose in the various situations by $r$, exposure time in years by $t$, and the total of the considered time period by $\mathrm{T}$ (ie, the "time window" of 20 a, 5 to 25 a prior to death), the described calculations were made according to

$$
\mathrm{GRI}=\sum_{\mathrm{ij}}^{\Sigma \Sigma \mathrm{rt} / \mathrm{T}}
$$

with summation over the three main activities, $i$, and over time periods, $j$, during the "time window." The background radiation, $r$, was taken as 2 for stone houses, 1 for wooden houses, and 1.5 for "mixed" types of houses (eg, plastered and/or brick houses) on a relative scale. In general, the minimum score always amounted to three points and the maximum score amounted to six in terms of this gamma radiation index. In the data analysis, three exposure levels were chosen, category I encompassing individuals with less than four points, category II being those with four but less than five points, and category III being those having achieved five points or more.

Exposure to other factors was directly obtained from the questionnaire and only crudely weighted with regard to intensity and duration, requiring a minimum of 1 a of exposure or at least five episodes of $\mathrm{X}$-ray examination or one series of treatment 5 a prior to death. Various leisuretime exposures to chemicals were disregarded as not fulfilling this requirement. Furthermore, all exposures beyond 20 a prior to death were disregarded, and no additional latency-time criterion was applied.

\section{Statistical methods}

The statistical analyses of the data were based on the Mantel-Haenszel procedures (27) and the Mantel extension of the Mantel-Haenszel test (26) with regard to trends over the categories of exposure. The principles applied for the determination of the standardized rate ratios have been outlined by Miettinen (29) along with useful principles for evaluating confounding (28) and a method for calculating the confidence interval of a rate ratio (31). 


\section{Results}

Out of the 42 cases and 244 referents finally included in the study, 71 and $55 \%$, respectively, were found to belong to exposure category II or III, ie, the crude rate ratio (odds ratio) was 2.1 and the Mantel-Haenszel point estimate 2.0 (table 1). There was a slight trend towards an exposure-effect relationship over the exposure categories [Mantel-extension, $\chi^{2}(1)$ $=3.34]$. Since concerns of validity might affect the reference entity with regard to violent deaths, as perhaps not being representative of the exposure frequency in the source population, the numbers of violent deaths are given in parentheses in table 1. However, the exclusion of violent deaths would have almost no influence on the measures of effect as reflected in the various rate ratios given in the table, and it seems appropriate, therefore, to include violent deaths among the referents.

Since there is only stratification for age in table 1 , there should be concern about other, uncontrolled confounders. To identify potential confounding factors, a number of crude rate ratio analyses were also undertaken according to table 2. They showed some effect of exposure to pesticides, X-ray treatment, contacts with animals, and solvent exposure, whereas the effects from other exposures were less pronounced. Furthermore, among the referents (table 3 ), there turned out to be a positive relationship between a low gamma radiation index and contacts with animals, as well as exposure to pesticides, ie, negative confounding, whereas the relationship to X-ray treatment was positive. Solvent exposure was comparatively common in category II of the gamma radiation index, whereas the distribution was similar for categories I and III. Due to the possible confounding properties of pesticides and X-ray treatment, the material was restricted through the exclusion of individuals with these risk indicators.

Table 1. Distribution of the cases of acute myeloid leukemia and the referents into categories of a gamma radiation exposure index, category I (lowest) being the reference. The numbers of violent deaths among the referents are given in parentheses.

\begin{tabular}{|c|c|c|c|c|}
\hline \multirow{2}{*}{$\begin{array}{l}\text { Age group } \\
\text { (a) }\end{array}$} & \multicolumn{4}{|c|}{ Category of gamma radiation index } \\
\hline & 1 & II & III & $I I+I I I$ \\
\hline \multicolumn{5}{|l|}{$20-49$} \\
\hline $\begin{array}{l}\text { Cases } \\
\text { Referents }\end{array}$ & $\begin{array}{r}1 \\
15\end{array}$ & $\begin{array}{l}2 \\
8(3)\end{array}$ & $\begin{array}{l}7 \\
21\end{array}$ & $\begin{array}{r}9 \\
29\end{array}$ \\
\hline \multicolumn{5}{|l|}{$50-69$} \\
\hline $\begin{array}{l}\text { Cases } \\
\text { Referents }\end{array}$ & $\begin{array}{c}3 \\
32(1)\end{array}$ & $\begin{array}{r}4 \\
21(0)\end{array}$ & $\begin{array}{l}11 \\
42 \text { (2) }\end{array}$ & $\begin{array}{l}15 \\
63(2)\end{array}$ \\
\hline \multicolumn{5}{|l|}{$\geq 70$} \\
\hline $\begin{array}{l}\text { Cases } \\
\text { Referents }\end{array}$ & $\begin{array}{c}8 \\
63(0)\end{array}$ & ${ }_{20}^{3}(0)$ & ${ }^{3} 2(0)$ & $\begin{array}{l}6 \\
12(0)\end{array}$ \\
\hline $\begin{array}{ll}\text { All } & \\
\text { Cases } \\
\text { Referents }\end{array}$ & $\begin{array}{r}12 \\
110\end{array}$ & $\begin{array}{r}9 \\
49\end{array}$ & $\begin{array}{l}21 \\
85\end{array}$ & $\begin{array}{r}30 \\
134\end{array}$ \\
\hline $\begin{array}{l}\text { Crude rate ratio } \\
\text { Standardized mortality ratio } \\
\text { Standardized rate ratio a } \\
\text { Mantel-Haenszel } \chi^{2}(1) \\
\text { Mantal-Haenszel rate ratio } \\
\text { Point estimate } \\
95 \% \text { confidence interval } \\
\text { Mantel extension for } \\
\text { the trend, } \chi^{2}(1)\end{array}$ & $\begin{array}{l}1.0 \\
1.0 \\
1.0\end{array}$ & $\begin{array}{l}1.7 \\
1.8 \\
1.6 \\
1.3\end{array}$ & $\begin{array}{l}2.3 \\
2.6 \\
1.8 \\
3.4\end{array}$ & $\begin{array}{c}2.1 \\
2.3 \\
1.8 \\
2.99 \\
\\
0.9-4.3\end{array}$ \\
\hline
\end{tabular}

a With exposure category $\mathrm{l}$ as the standard. 
(The exclusion of individuals with pesticide exposure made the material homogeneous with respect to animal contacts as well.) The results are shown in table 4; the material was somewhat "strengthened," although the trend for the standardized rate ratio became less clear, seemingly due to the influence from solvent exposure (table 3 ). Stratifying on solvent exposure in addition to age resulted in table 5 with a relatively strong trend over the exposure categories [Mantel-extension for the trend $\left.\chi^{2}(1)=4.07\right]$. Notice the lack of positive confounding from solvents between exposure category I and III in table 3 and the rather strong $\chi^{2}(1)=5.12$ in table 4 . The tendency towards (a numerically strong) effect modification from solvent exposure is noteworthy. Evaluating table 5 with regard to the effect from solvents resulted in a crude rate ratio of 6.0. Mantel-Haenszel $\chi^{2}(1)=12.25$, the MantelHaenszel rate ratio being 6.7 with an approximate $95 \%$ confidence interval of 2.1-14.4. It was not possible to obtain any more-detailed and definite information

Table 2. Status or exposure (especially risk indicators were selected for this table) among the cases and referents along with estimates of the crude rate ratio.

\begin{tabular}{|c|c|c|c|}
\hline \multirow{2}{*}{$\begin{array}{l}\text { Status or } \\
\text { exposure }\end{array}$} & \multicolumn{2}{|c|}{ Number of individuals exposed or with status } & \multirow{2}{*}{$\begin{array}{c}\text { Crude rate } \\
\text { ratio }\end{array}$} \\
\hline & Cases $(N=42)$ & Referents $(\mathrm{N}=244)$ & \\
\hline Male gender & 23 & 121 & $\uparrow .2$ \\
\hline Pesticides & 3 & 6 & 3.1 \\
\hline X-ray treatment & 4 & 20 & 1.2 \\
\hline X-ray examination & 12 & 68 & 1.0 \\
\hline Animal contacts & 16 & 79 & 1.3 \\
\hline Cats & 14 & 62 & 1.5 \\
\hline Poultry & 8 & 36 & 1.4 \\
\hline Cattle & 10 & 43 & 1.5 \\
\hline Solvent exposure & 11 & 13 & 6.3 \\
\hline Smoker & 19 & 117 & 0.9 \\
\hline Rural domicile & 11 & 59 & 1.1 \\
\hline
\end{tabular}

Table 3. Relationship between gamma exposure category and occurrence of exposure to other risk indicators (according to evaluation in table 2) indicating confounding (positive or negative) through the odds ratio in reference to exposure category $I$.

\begin{tabular}{|c|c|c|c|}
\hline \multirow{2}{*}{ Risk indicator } & \multicolumn{2}{|c|}{ Referents } & \multirow{2}{*}{ Odds ratio a } \\
\hline & Exposed & Nonexposed & \\
\hline \multicolumn{4}{|l|}{ Pesticides } \\
\hline $\begin{array}{l}\text { Exposure category I } \\
\text { Exposure category II } \\
\text { Exposure category III }\end{array}$ & $\begin{array}{l}6 \\
0 \\
0\end{array}$ & $\begin{array}{r}104 \\
49 \\
85\end{array}$ & $\frac{1.0}{-}$ \\
\hline \multicolumn{4}{|l|}{ X-ray treatment } \\
\hline $\begin{array}{l}\text { Exposure category I } \\
\text { Exposure category II } \\
\text { Exposure category III }\end{array}$ & $\begin{array}{l}8 \\
5 \\
7\end{array}$ & $\begin{array}{r}102 \\
44 \\
78\end{array}$ & $\begin{array}{l}1.0 \\
1.5 \\
1.1\end{array}$ \\
\hline \multicolumn{4}{|l|}{ Animal contacts } \\
\hline $\begin{array}{l}\text { Exposure category I } \\
\text { Exposure category II } \\
\text { Exposure category III }\end{array}$ & $\begin{array}{r}62 \\
14 \\
3\end{array}$ & $\begin{array}{l}48 \\
35 \\
82\end{array}$ & $\begin{array}{l}1.0 \\
0.3 \\
0.3\end{array}$ \\
\hline \multicolumn{4}{|l|}{ Solvent exposure } \\
\hline $\begin{array}{l}\text { Exposure category I } \\
\text { Exposure category II } \\
\text { Exposure category III }\end{array}$ & $\begin{array}{l}5 \\
5 \\
3\end{array}$ & $\begin{array}{r}105 \\
44 \\
82\end{array}$ & $\begin{array}{l}1.0 \\
2.4 \\
0.8\end{array}$ \\
\hline
\end{tabular}

a Exposure category I being the reference. 